\begin{tabular}{ll}
\hline Journal of National Institute of Neurosciences Bangladesh, & ISSN (Online) $2518-6612$ \\
July 2019, Vol. 5, No. 2, pp. 172-176 & ISSN (Print) $2410-8030$
\end{tabular}

\title{
Study on Superstitions Related to Pregnancy
}

\author{
Zinia Sultana ${ }^{1}$, Liza Chowdhury ${ }^{2}$, Nahid Reaz Shapla ${ }^{3}$ \\ ${ }^{1}$ Classified Specialist, Department of Gynaecology \& Obstetrics, Combined Military Hospital, Dhaka, \\ Bangladesh; ${ }^{2}$ Professor \& Head, Department Gynaecology \& Obstetrics, Combined Military \\ Hospital, Dhaka, Bangladesh; ${ }^{3}$ Classified Specialist, Department of Gynaecology \& \\ Obstetrics, Combined Military Hospital, Dhaka, Bangladesh
}

[Received: 12 Januray 2019; Accepted: 12 May 2019; Published: 1 July 2019]

\begin{abstract}
Background: During pregnancy, there are many superstitions throughout the world, especially in the developing countries like Bangladesh. Objective: This study was aimed to know the status of superstitions related to pregnancy among people. Methodology: This descriptive type of cross-sectional study was conducted in the outpatient of department in Combined Military Hospital, Dhaka, Bangladesh from January 2018 to March 2018 for a period of three months. Total 96 persons were recruited after taking verbal consent. Result: Among the study group having at least one superstition was in $69.8 \%$ of total participants showing in figure 1. In 25 to 40 years of age group the superstitions were more common and it was $85.0 \%$ showing in table1. On the educational background, illiterate group having more superstitions $81.13 \%$, primary education group $65.21 \%$, SSC $50 \%$ and above SSC $33.33 \%$ showing in table 3 . On the basis of gender, male $(58.233 \%)$ and Female $(71.42 \%)$ were superstitious in at least one superstition. On the basis of socioeconomic status, lower class $92.72 \%$, lower middle class $54.54 \%$ and middle class $21.05 \%$ were superstitious in at least one superstition. On the basis of occupation, housewives $(89.90 \%)$, students $(16,66 \%)$, service holder $(30 \%)$ and farmer $(50 \%)$ having at least one superstitious. On the basis of religion; the superstitious individuals were Muslim 59\%, Hindu 97\%, and others $67.16 \%$. Conclusion: Superstitions related to pregnancy are very common in Bangladesh. Superstitious are more related to illiteracy, low socioeconomic condition and with house wives who remain inside. [Journal of National Institute of Neurosciences Bangladesh, 2019;5(2): 172-176]
\end{abstract}

Keywords: Nutrition; pregnant women; food taboos; traditional beliefs

Correspondence: Major Zinia Sultana, Classified Specialist, Department of Gynaecology \& Obstetrics, Combined Military Hospital, Dhaka, Bangladesh; Mailing Address: 152/3, Staff Road, Dhaka Cantonment, Dhaka-1206; Email: drzinia.sultana@gmail.com; Cell no.: +8801768874141 ;

Conflict of interest: There is no conflict of interest relevant to this paper to disclose.

Funding agency: This research project was not funded by any group or any institution.

Contribution to authors: Sultana Z, Chowdhury L have contributed from the protocol preparation, data collection up to report writing. Manuscript writing was performed by Sultana Z. Statistical analysis was performed by Sultana Z. Sultana Z, Chowdhury L, Shapla NZ have involved in revision of manuscript.

How to cite this article: Sultana Z, Chowdhury L, Shapla NZ. Study on Superstitions Related to Pregnancy. J Natl Inst Neurosci Bangladesh, 2019;5(2): 172-176

Copyright: (C2019. Sultana et al. Published by Journal of National Institute of Neurosciences Bangladesh. This article is published under the Creative Commons CC BY-NC License (https://creativecommons.org/licenses/by-nc/4.0/). This license permits use, distribution and reproduction in any medium, provided the original work is properly cited, and is not used for commercial purposes.

\section{Introduction}

Superstition is a belief or practice resulting from ignorance, fear of the unknown, trust in magic or chance, or a false conception of causation. An irrational abject attitude of mind toward the supernatural, nature, or God resulting from superstition ${ }^{1}$.

The development in science and technology has helped us to overcome the superstitions associated with pregnancy, still many of us follow them even though we realize that these lack scientific evidence. As in many other things in life, numerous traditions have been created. They often have nothing with science. They are usually prejudices that become part of a local culture. Traditional beliefs and attitudes influence women's health. Even when women have access to appropriate healthcare, they often prefer home/community based care $^{1}$. Women's overall health and nutritional status, pregnancy outcomes and other reproductive health problems are considered to be the major biological causes of maternal mortality; therefore, the overall nutritional status of a pregnant woman is principally determined by the feeding practices and care facilities available to her ${ }^{2}$. During pregnancy mothers have to stay in a vulnerable position. They always remain in fear 
about their coming babies and anticipate the worse. Sometimes when babies are born with physical defect, mothers tend to think that they did something wrong previously and it is for punishment. For these reasons mothers become superstitious ${ }^{3}$.

Forms of superstitions become different with religions, geography and time. There are many traditional beliefs and also some religious habits related to pregnancy. Some of these beliefs like restricted diet and traditional religious modes of treatment put the mother and child health in risk. There are various types of superstitions related to pregnancy in our country. Sometimes people believe pregnant mothers should not eat sufficient as necessary for growth of the baby, some elderly women believe taking nutritious food during pregnancy causes big baby and create problems during normal delivery. The importance of nutrition in pregnancy and its implication on pregnancy outcome and subsequent maternal and fetal health is well established. Pregnancy demands additional nutrition requirements, and pre-pregnancy counselling on dietary requirement during pregnancy is an essential component of good prenatal care $^{3}$. A food taboo is a prohibition of certain foods during pregnancy and lactation. Unfortunately, the traditional beliefs or food myths are widely practiced.

Evidences have shown that the majority of women adhere to traditional beliefs in their eating habits during pregnancy and lactation ${ }^{4}$. As a result mother takes inadequate food, so baby born under-weight. Some dietary habit is the modern equivalent of a superstition. If something bad happens then they blame it on that one pineapple or papaya ate, but in reality it may be nothing more than a coincidence ${ }^{1}$. Sometimes women believe that the pregnant woman should not cut anything during solar eclipse. If they do, there is every possibility of having an abnormal baby and it is nothing but a wrong belief ${ }^{5}$.

Expectant mothers from Mexico and parts of Latin America frequently wear bright red panties with a safety pin, seems to those tribes believed that the eclipse released energy that could cause birth defects ${ }^{6}$. A Maisin woman from Papua New Guinea whose baby was born with cord around its neck may then remember having walked through a spider's web during her pregnancy ${ }^{3,5}$. In Indonesia, pregnant women not to sit in door entrance because they belief baby may find it difficult to come out $^{6}$. Thai women eat lotus buds which have been chanted over by a Buddhist monk so that their bodies will open up like a lotus flower and they will give birth easily $^{5}$. Sometimes superstitions may actually be beneficial as research support the idea that a mother's emotion can affect baby's condition in the uterus. In Thailand it is believed that every sound, sight, touch, taste, smell, thought and action experienced by mother will have some effect on the child ${ }^{6}$. Nigerian mothers are encouraged to avoid places where people fight and quarrel so that the ensuing baby becomes peace loving?

Sometimes pregnant women wear band around their umbilicus with firm belief that baby cannot go upward and normal delivery will be easier and smooth ${ }^{5}$. This present study was undertaken to know the status of superstitions related to pregnancy among people.

\section{Methodology}

This was a descriptive type of cross sectional study, in which persons were selected on random basis from January 2018 to March 2018 in outpatient department of $\mathrm{CMH}$ Dhaka. There were no ethical problems, as before interview verbal consent was taken. Cases were selected according to inclusion and exclusion criteria. Relevant information were taken according to questionnaire. Common superstitions in different aspects of daily activities in the country were related to food supplements, routine physical cheek up of mother, maternal daily activities and mode of delivery, Solar eclipse, Traditional religious treatment. Though the study was performed in CMH Dhaka it actually reflects the condition of whole population of Bangladesh. People of various area of the country visit for ANC in Gynae OPD of CMH Dhaka. All pregnant women and person having at least a child within 2 years in family included in this study.

\section{Results}

A total number of 96 persons were recruited. In this study the number of participants having at least one superstition was 67 which was $69.79 \%$ of total participants (Figure I).

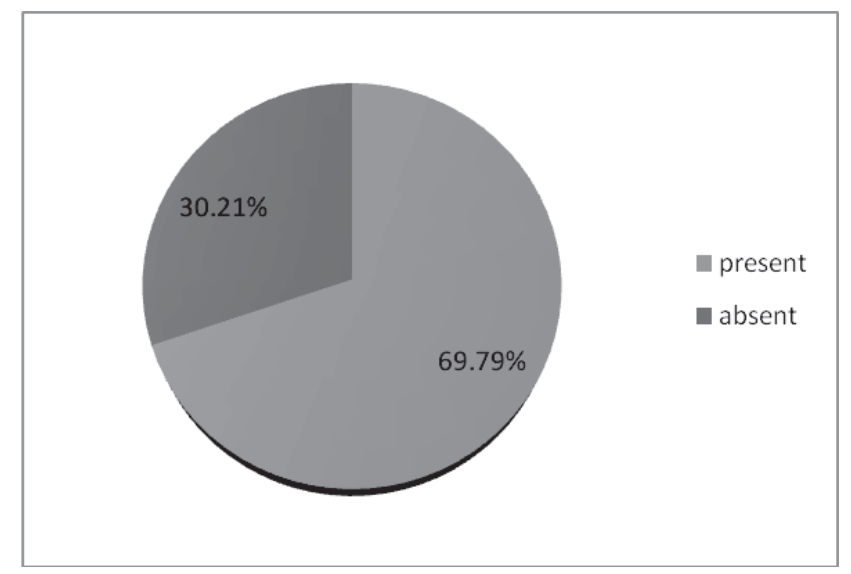

Figure I: Number of perticipants having at least one superstition 
Superstitions were more among 25 to 40 years age group, which was $85 \%$ cases (Table 1 ).

Table 1: Age distribution among the study population related to superstition.

\begin{tabular}{lcc}
\hline Age group & Frequency & Percent \\
\hline$<25$ years & 35 & 57.14 \\
25 to 40 years & 20 & 85 \\
$>40$ years & 41 & 73.17 \\
\hline
\end{tabular}

Female were more superstitious than male which was $71.42 \%$ and $58.33 \%$ respectively (Table 2 ).

Table 2: Superstitious related to gender

\begin{tabular}{lcc}
\hline Gender & Frequency & Percent \\
\hline Male & 12 & 58.33 \\
Female & 84 & 71.42 \\
\hline
\end{tabular}

Illiterate persons were more superstitious (81.130) than primary, secondary and higher secondary educated group which were $65.21 \%, 50 \%$ and $33.33 \%$ respectively (Table 3 ).

Table 3: Educational status among the study population

\begin{tabular}{lcc}
\hline Educational status & Frequency & Percent \\
\hline Illiterate & 53 & 81.13 \\
Up to primary & 23 & 65.21 \\
Up to SSC & 14 & 50 \\
Above SSC & 6 & 33.33 \\
\hline
\end{tabular}

Lower class were more superstitious than economically solvent group. Lower class, lower middle class and middle class were superstitious $92.72 \%, 54.54 \%$ and $21.05 \%$ respectively (Table 4 ).

Table 4: Socioeconomic economic status among the study group

\begin{tabular}{lcc}
\hline Socioeconomic status & Frequency & Percent \\
\hline Lower class & 55 & 92.72 \\
Lower middle class & 22 & 54.54 \\
Middle class & 19 & 21.05 \\
\hline
\end{tabular}

Superstitions were more in housewives, about $89.90 \%$ than others population like student, farmer and service holder were $16.7 \%, 50 \%$ and $30 \%$ respectively (Table 5).

Table 5: Occupational status among the study population

\begin{tabular}{lcc}
\hline Occupation & Frequency & Percent \\
\hline House wife & 57 & 89.9 \\
Student & 2 & 16.7 \\
Farmer & 5 & 50.0 \\
Service holder & 3 & 30.0 \\
\hline
\end{tabular}

Superstitions were more common in Hindu religion, about $89 \%$ than Muslim and others which were 50\% cases and $66.16 \%$ cases respectively (Table 6).

Table 6: superstition among the religion group

\begin{tabular}{lcc}
\hline Religion Group & Frequency & Percent \\
\hline Muslim & 82 & 50.0 \\
Hindu & 11 & 89.0 \\
Others & 03 & 66.16 .0 \\
\hline
\end{tabular}

Number of persons with individual superstitions were recorded (Table 7).

Table 6: superstition among the religion group

\begin{tabular}{llc}
\hline Name of superstition & Reasons for belief & Percent \\
\hline $\begin{array}{l}\text { Food supplements } \\
\text { Regular ante }\end{array}$ & $\begin{array}{l}\text { Extra calorie causes big baby } \\
\text { No benefit }\end{array}$ & 33.0 \\
$\begin{array}{l}\text { natal cheek up } \\
\text { Maternal activity and }\end{array}$ & $\begin{array}{l}\text { Physical activity is harmful } \\
\text { for mother and coming baby }\end{array}$ & 10.0 \\
$\begin{array}{l}\text { Sode of delivery } \\
\text { Radiate energy that is }\end{array}$ & 16.0 \\
$\begin{array}{l}\text { Maternal physique and } \\
\text { fetal gender }\end{array}$ & $\begin{array}{l}\text { Mother look more fair if } \\
\text { carrying female fetus }\end{array}$ & 26.0 \\
$\begin{array}{l}\text { colostrum } \\
\text { Traditional and } \\
\text { religions treatment }\end{array}$ & $\begin{array}{l}\text { Colostrum is harmful for baby } \\
\text { vaginal delivery }\end{array}$ & 7.0 \\
\hline
\end{tabular}

\section{Discussion}

On the study several factors were found to be the influencing for prevailing superstitions. Those ware poor socioeconomic condition, illiteracy, lack of maternal and child health care knowledge, occupational limitation.

Bangladesh is the $9^{\text {th }}$ most populous country in the world. It has higher birth rates as compared to developed countries ${ }^{7}$. Every couple wants a safe delivery \& a healthy baby. Findings revealed that some traditional customs particularly those relating to safety of the mother and baby during perinatal period were adhered to bangali families. We reports common myths prevalent during pregnancy and after delivery. There was no scientific basis behind the myths and even they may cause injury to mother or baby.

Educational and socioeconomic status were the most important factors to cause variation in the response from participants regarding superstitions. Among illiterate people percentage of superstitions is $81.13 \%$ while in people with education level more than SSC it is only $33.33 \%$. Among the participants having 
educational level below primary education and above primary education the percentage of superstition is $65.21 \%$ and $50 \%$ respectively. So education was an influencing factor which had a direct effect on percentage of superstitions. Education level among study population was range from illiterate to post graduate. The illiterate women followed the myth more commonly than educated women. Possibly it was because of better knowledge of science and less beliefs on myths in educated mothers.

Ekwochi et al noted a relationship between traditional post-partum practices and demographic characteristics of woman such as age, educational status, age at marriage and birth place ${ }^{8}$. Epidemiological studies from developing countries highlight that imbalance diets negatively affect fetoplacental growth and long-term consequences on offsprin ${ }^{7-8}$. This combined effect of under-nourishment and negative food practice added more impact on maternal health in these countries. The adverse fetal outcome as a result of poor maternal nutrition was the leading causes of neonatal death excluding congenital anomalies in developing countries 9 . Introducing proper nutritional programs and adequate antenatal care will save lives of many mothers and children in developing countries.

Among people with lower class socioeconomic status the superstition percentage was $92.72 \%$ while among people with middle class the percentage was $21.1 \%$. In between these two the lower middle class having the percentage of $54.54 \%$ proved that the percentage of superstition has direct relationship to poverty. Women of rural background had higher prevalence than urban women. Possible reasons were low education, poor socio-economic status and lack of awareness about health facilities.

Another factor was occupation of the participants. Those who were to spend their life solely inside the house like house wives have more superstitions than those who were to go outside the house at least for the sake of occupation like service holder, student etc. Percentage of superstition among house-wife, service-holder, and student is $89.90 \%, 30 \%$, and $16.66 \%$ respectively. There were also differences of superstitions percentages on the basis of age and gender difference as evidenced by the superstitions percentages $57.14 \%, 85 \%, 73.17 \%$ and $58.33 \%$, $71.42 \%$ among the $<25$ years, 25 to 40 years and $>40$ years age groups and male, female gender groups respectively. Study revealed that there was a significant association between women endorsed prohibiting of foods were younger age group, low level of education, living in rural areas and had inadequate antenatal care. Similarly, a community-based study conducted in Saki East Local Government of Oyo state, Nigeria, authors found that food taboos significantly associated with teenage, primigravida, lack of formal education, and low-income family ${ }^{10}$. Similar results of association were obtained by Zerfu et al. In many African countries, there were an urban rural disparity in health services. Failure to deliver essential medical and social services in rural areas may be a significant predictor of many health problems in developing countries including food taboos ${ }^{11}$.

\section{Conclusion}

Superstitions related to pregnancy are very common in Bangladesh. In this study the superstitions were more among illiterate, low socioeconomic status and in the Hindu religion. The impact of superstitions is a great health hazard in developing country like Bangladesh. Poverty and illiteracy were two major factor behind the generation and proliferation of superstitions.

\section{References}

1. Zahid H, Absar C. Caritas battles pregnancy superstitions in Bangladesh. Web site: https://www.ucanews.com/story-archive/?post_name=/2010/08/1 1/caritas-battles-pregnancy-superstitions\&post id $=61644$

2. Tietjen AM. Infant care and feeding practices and the beginnings of socialization among the Maisin of Papua new Guinea Ecology of food \& nutrition. 1984; 15(4): 39-78

3. Kunna A, abdelgadir Shaaeldin M, Alsammani MA. Superstitious Food Beliefs and Traditional Customs among Ladies Attending the Antenatal Clinic at Omdurman Maternity Hospital (OMH), Omdurman, Sudan. Annals of Medical and Health Sciences Research. 2017; 7(4) 41-56

4. Wang XL, Wang Y, Zhou SZ. Puerperal practice pattern in a rural area of north China. Beijing Da Xue Xue Bao. 2007 Apr 18; 39:140-144

5. Vasilevski V, Carolan-Olah M. Food taboos and nutrition-related pregnancy concerns among Ethiopian women. J Clin Nurs. 2016; 20(2):3069-3075

6. Ahmed S, Abdullahi H, Adam I. Practice of pica among pregnant women in Khartoum. Sudan. Int J Gynaecol Obstet. 2012; 11(8):71-72

7. Grieger JA, Clifton VL. A review of the impact of dietary intakes in human pregnancy on infant birth weight. Nutrients. 2014; 29(7):153-178

8. Hossain B, Sarwar T, Reja S, Akhter MN . Nutritional Status of Pregnant Women in Selected Rural and Urban Area of Bangladesh. Journal of Nutrition \& Food Sciences.2013;03(1)4-16

9. Ekwochi U, Osuorah CD, Ndu IK, Ifediora C, Asinobi IN, Eke CB. Food taboos and myths in South Eastern Nigeria: The belief and practice of mothers in the region. J Ethnobiol Ethnomed. 2016; 27(12):17-31

10. Oluwafolahan OS, Catherine AB, Olubukunola AJ. Dietary habits of pregnant women in Ogun-East Senatorial Zone, Ogun State, Nigeria: A comparative study. International Journal of Nutrition and Metabolism. 2014;6(4):42-94 
11. Abubakar A, Holding P, Mwangome M. Maternal perceptions of factors contributing to severe under- nutrition among children in a rural African setting. Rural Remote Health survey and Research 2011; 5(4):14-25

12. Zefru A, Umetand M, Baye k. Dietary habits, food taboos, and perceptions towards weight gain during pregnancy in Arsi, rural central Ethiopia. Journal of Health, Population and Nutrition.2016;
22(4):22-35

13. Sumeya A, Abdelillah K, limia S, Mohamed abdelgadir S, Mohamed Alkhatim A. Superstitious Food Beliefs and Traditional Customs among Ladies Attending the Antenatal Clinic at Omdurman Maternity Hospital (OMH), Omdurman, Sudan Annals of Medical and Health Sciences Research. 2017; 7(4): 45-47 